\title{
Fatigue behavior of Ti-6Al-4V alloy modified by plasma immersion ion implantation: temperature effect.
}

\author{
Verônica Velloso ${ }^{1, *}$, Leonardo Nozaki ${ }^{1}$, Diego Tapia ${ }^{2}$, Maria Odila Cioffi ${ }^{1}$, Rogério Oliveira ${ }^{3}$, Miguel Barboza $^{4}$, and \\ Herman Voorwald ${ }^{l}$ \\ ${ }^{1}$ Faculdade de Engenharia de Guaratinguetá - FEG/UNESP, Materials and Technology Department, Fatigue and Aeronautical Materials \\ Research Group, Av. Ariberto Pereira da Cunha 333, Brazil \\ ${ }^{2}$ Universidad Nacional de Ingeniería - UNI, Faculty of Mechanical Engineering, Av. Túpac Amaru 210, Peru \\ ${ }^{3}$ Instituto Nacional de Perquisas Especiais - INPE, Associated Laboratory of Plasmas, Av. dos Astronautas 1758, Brazil \\ ${ }^{4}$ Escola de Engenharia de Lorena - EEL/USP, Materials Department, Pólo-Urbo Industrial Gleba AI-6, Brazil
}

\begin{abstract}
This research studied Ti-6Al-4V alloy behavior with two (2) different microstructure subjected to nitrogen addition by PIII treatment, with and without sample heating, under cyclic load. PIII conditions, at $390{ }^{\circ} \mathrm{C}$, were DC voltage of $9.5 \mathrm{kV}$, frequency of $1.5 \mathrm{kHz}$ and pulse of $40 \mu \mathrm{s}$. PIII conditions, with sample heating at $800{ }^{\circ} \mathrm{C}$, were $7 \mathrm{kV}, 0.4 \mathrm{kHz}$ and $30 \mu \mathrm{s}$. Axial fatigue tests were performed on untreated and treated samples for resistance to fatigue comparison. The untreated Ti-6Al-4V had an annealed microstructure, PIII treatment at $390{ }^{\circ} \mathrm{C}$ resulted in a microstructure that has no nitride layer or diffusion zone. In the PIII treatment at $800{ }^{\circ} \mathrm{C}$, the microstructure presented nitride layer and diffusion zone. Resistance to fatigue decreased with PIII treatments in both temperatures. At $390{ }^{\circ} \mathrm{C}$, the treatment created deformation regions and cracks on surface due to nitrogen implantation that formed solid solution with titanium and imposed lattice strains on the crystal lattice. At $800{ }^{\circ} \mathrm{C}$, bulk ductility decrease, increasing of $\alpha \mathrm{Ti}$ proportion in microstructure due to $\alpha$ case formation and the presence of a ceramic layer dropped fatigue resistance of Ti-6A-4V alloy.
\end{abstract}

\section{Introduction}

Industry applies titanium alloys in the biomedical, petrochemical, automotive and aeronautical field. The aeronautical industry accounts for about $80 \%$ of all worldwide titanium demand and is, therefore, the main application field, being Ti-6Al-4V alloy the most used of the titanium alloy family. Its main properties are mechanical resistance at room and high temperatures (up to $350{ }^{\circ} \mathrm{C}$ ), corrosion resistance, biocompatibility, toughness, formability and, most important for the aircraft industry, high specific strength and good damage tolerance. Titanium alloys have the highest specific resistance among structural materials, which means that they are as light as aluminum alloys and mechanical resistant as microalloyed steel [1-4].

Most of structural components, during their useful life, are subjected to cyclic loading. Even though the applied stress is below the yield strength $\left(\sigma_{\mathrm{ys}}\right)$, these components may fail due to fatigue. This failure mode involves nucleation, crack propagation stages and subsequent catastrophic failure (including materials that exhibit ductile behavior). Among the aspects that change fatigue life, surface characteristics are critical because, in most cases, crack nucleation starts at the surface $[5,6]$.

Aircraft turbine engines are made of titanium and nickel superalloys. Aeronautical applications search for lightweight materials. In the case of turbines, however, the material must be able to withstand high loads, during service, at high temperatures. Therefore, the material needs to ensure safe and continuous operation of the engine [7].

Surface treatments intend to improve the surface quality of the metallic component increasing its useful life. The literature reported several studies that investigated the mechanical behavior of metallic alloys subjected to surface treatments [8-13]. Plasma immersion ion implantation (PIII) is a technique that showed good results related to the increase in surface hardness, corrosion resistance and decrease friction coefficient, producing no residues [14-17]. However, there is a lack of studies relating PIII treatment with the fatigue behavior of titanium alloys. This research aims to study Ti-6Al-4V alloy behavior with two (2) different microstructure subjected to nitrogen addition by PIII treatment, with and without sample heating, submitted to axial fatigue.

\section{Materials and methods}

The Ti-6Al-4V alloy was used in rod form with a diameter of $14 \mathrm{~mm}$ and a length of $1 \mathrm{~m}$. Specimen preparation followed metallographic patterns: hot mounting, polishing and etching with Kroll's solution 
(1\% HF, 4\% HNO3 and distillate water). Optical microscopy was used to image the samples.

The PIII system consists of a vacuum chamber with a specimen holder, plasma source and a high voltage pulses modulator. The treatment conditions were $\mathrm{T}=$ $390{ }^{\circ} \mathrm{C}$, DC voltage of $9.5 \mathrm{kV}$, frequency of $1.5 \mathrm{kHz}$ and pulse of $40 \mu \mathrm{s}, \mathrm{t}=2 \mathrm{~h}$; and with an auxiliary system of sample heating at $800^{\circ} \mathrm{C}$, were $7 \mathrm{kV}, 0.4 \mathrm{kHz}$ and $30 \mu \mathrm{s}$, $\mathrm{t}=2 \mathrm{~h}$.

Ti-6Al-4V alloy was characterized by X-ray diffraction. The following conditions were used: $40 \mathrm{kV}$;

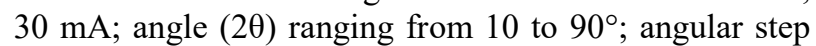
of $0.05^{\circ}$ and $1 \mathrm{~s}$ count time per point. The analysis was performed at room temperature with $\mathrm{Cu}-\mathrm{K} \alpha$ radiation and a graphite monochromator.

An optical profilometer, Leica DCM3D model, was used to calculate the surface roughness parameters. The measured area was $1.27 \times 0.95 \mathrm{~mm}^{2}$. The surface roughness was measured before and after PIII treatment. The parameters were calculated using Gwyddion software and used in notch sensitivity analysis.

Axial fatigue tests were conducted until fracture or $10^{6}$ cycles, for $\mathrm{R}=0.1$ and $10 \mathrm{~Hz} . \mathrm{S} \times \mathrm{N}$ curves were raised for untreated and PIII treated conditions. Data were analyzed statistically by Log-Normal. Figure 1 shows the specimen made according ASTM E466.

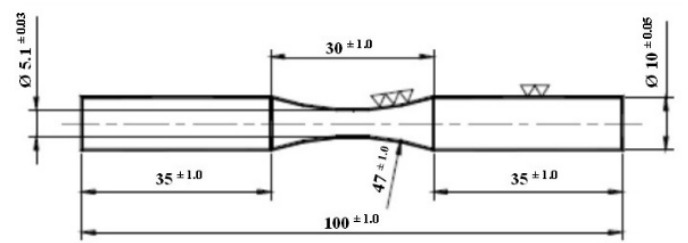

Fig. 1. Axial fatigue testing specimen.

\section{Results and discussion}

Figures 2 and 3 show Ti6Al4V alloy microstructure at annealed and lamellae conditions. The latter is also known as Widmanstätten morphology, characterized by colonies arrangement and the coarse grains.

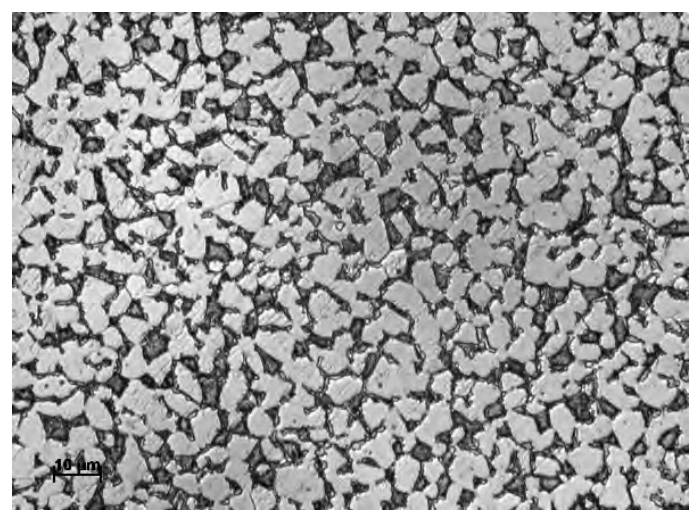

Fig. 2. Optical microscopy image of Ti-6Al-4V alloy: annealed condition.

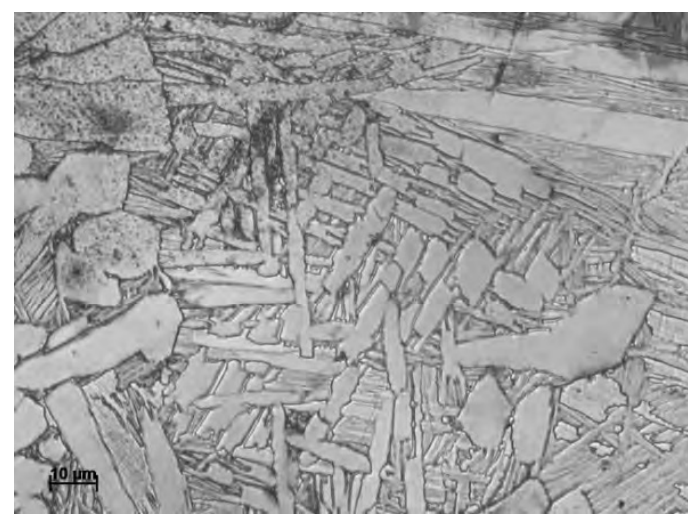

Fig. 3. Optical microscopy image of Ti-6Al-4V alloy: Widmanstätten condition.

Annealed Ti6Al4V alloy was subjected to PIII treatment at $800{ }^{\circ} \mathrm{C}$ and had the microstructure changed during the treatment. This transformation was due to the treatment temperature which is close to $\beta$ transus and, therefore, allowed the diffusion process in the titanium alloy microstructure [18].

The PIII treatment carried out at 390 and 800 ${ }^{\circ} \mathrm{C}$ modified the Ti6Al4V alloy in the following ways: $-390{ }^{\circ} \mathrm{C}$ (PIII - 390), the treatment temperature resulted from nitrogen bombardment on surface through the combination of voltage (power) and frequency parameters. The power and $\mathrm{N}^{+}$collisions amount on the alloy surface release energy as heat, increasing the environment temperature. In this case, it is said that the treatment was cold, because the sample was not heated and the work temperature remained $40 \%$ lower than Ti6Al4V alloy melting temperature. Thus, the nitrogen implantation on surface was ballistics and allowed nitrogen diffusion in some planar distances $[19,20]$. As a result, there was not observed a nitride layer or a stabilized $\alpha$ phase zone (since nitrogen is an $\alpha$ stabilizer) on surface. This treatment allowed the nitrogen solubilization on titanium, straining the titanium crystalline lattice solid-solution;

- $800{ }^{\circ} \mathrm{C}$ (PIII - 800), the treatment temperature was reached through an auxiliary sample heating system. The combination of the heat generated by the auxiliary heating system + nitrogen bombardment resulted in local temperature increase. Therefore, the treatment temperature achieved levels higher than $\beta$ transus, ie exceeded the transformation limit $\alpha \rightarrow \beta$ and provided atomic diffusion even in the bulk microstructure [21]. As the annealed type microstructure is unstable at high temperatures, the bulk morphology changed to a lamellae type, also known as Widmanstätten morphology. In addition, nitrogen implantation modified the surface, creating a layer of $13.4 \mu \mathrm{m}$ thickness (nitride layer, $1.4 \mu \mathrm{m}+$ diffusion region, $\alpha$ case). Figure 4 shows the modified surface of Ti6Al4V through nitrogen implantation in PIII- 800 condition. 


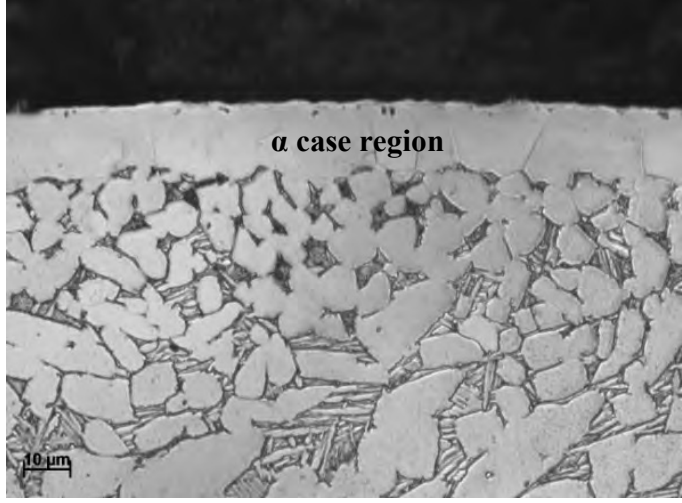

Fig. 4. Optical microscopy image of Ti-6Al-4V alloy: nitride layer $+\alpha$ case.

Figure 5 shows XRD analysis of Ti6Al4V alloy at untreated, PIII - 390 and PIII - 800 conditions.

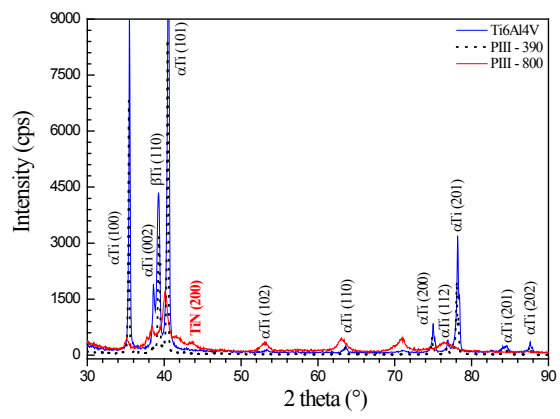

Fig. 5. DRX analysis of Ti6Al4V alloy for untreated, PIII - 390 and PIII - 800 treated conditions.

The highest intensity peaks were related to the $\alpha$ phase, which was found at $2 \theta=35.4^{\circ}, 38.4^{\circ}, 40.1^{\circ}$ and $77.7^{\circ}$. A small amount of $\beta$ phase was observed, characterized by the peak related to (110) plane and found at $2 \theta=39.6^{\circ}$. The DRX analysis at PIII -390 condition did not present nitrites. Since, at this condition, there was no formation of a nitrided layer and only nitrogen solubilization in the titanium crystalline lattice. While at PIII - 800 condition, the presence of the peak related to the plane (200) that corresponds to TiN compound was observed.

Figure 6 shows the $\mathrm{S}$ vs $\mathrm{N}$ curves of Ti6Al4V alloy at the untreated, PIII - 390 and PIII - 800 conditions.

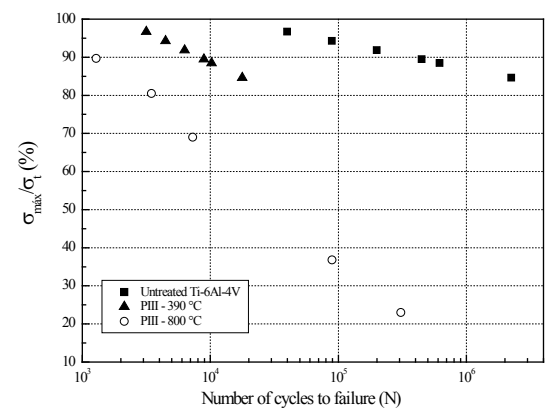

Fig. 6. S x N curves of Ti-6Al-4V alloy for untreated, PIII 390 and PIII - 800 treated conditions.

Equations 1 to 3 represent the curves generated by the Log-Normal model for untreated, PIII - 390 and PIII - 800 conditions, respectively:

$\log N=18.6-0.014 \sigma$

$\log N=9.5-0.006 \sigma$

$\log N=6.1-0.0029 \sigma$

The tensile testing results of the sample treated at PIII - 800 condition showed that the tensile strength limit $\left(\sigma_{t}\right)$ increased by $5 \%$ and that the ductility decreased by half. Thus, Figure 6 shows on the ordinate axis a relationship $\sigma_{\max } / \sigma_{t}$.

Figure 6 analysis showed that, for a stress level of $89 \% \sigma_{\mathrm{t}}$, the fatigue life time was equal to $4.5 \times 10^{5}$ cycles on untreated condition, $8.9 \times 10^{3}$ cycles on PIII 390 condition and $1.3 \times 10^{3}$ cycles on PIII -800 condition. Meaning a decreasing in fatigue life by the PIII treatment of 50 times for PIII - 390 condition and 346 times for PIII - 800 condition.

Based on the equations 1 to 3 generated by the statistical analysis Log-Normal, fatigue resistance was calculated for $\mathrm{N}=10^{3}$ and for $\mathrm{N}=10^{7}$. The values were $1058 \mathrm{MPa}$, when $\mathrm{N}=10^{3}$, and $840 \mathrm{MPa}$, when $\mathrm{N}=10^{7}$ for untreated condition. At PIII - 390 condition, fatigue resistance was equal to $1080 \mathrm{MPa}$, when $\mathrm{N}=10^{3}$, and $417 \mathrm{MPa}, \mathrm{N}=10^{7}$. Finally, at PIII -900 condition, fatigue resistance was equal to $1120 \mathrm{MPa}$, when $\mathrm{N}=10^{3}$, and $117 \mathrm{MPa}, \mathrm{N}=10^{7}$. The results showed that the surface treatments influenced the fatigue behavior of Ti6Al4V alloy in the high cycle fatigue region.

One of the goals of the notch sensitivity tests to fatigue behavior studies is to evaluate the crack initiation process. Simulating, thus, a real situation where a structural component contains in its design and structure defects and irregularities that act as stress concentrators points [22]. Arola and Ramulu [23] proposed a mathematical model, based on the notch sensitivity calculations, to define the surface features effect on stress concentration factor $\left(\overline{K_{t}}\right)$ of ceramic-polymer composites. Later, Arola and Williams [24] applied this mathematical model together with the Neuber rule for HSLA steels to evaluate the fatigue behavior dependence of average roughness $(\mathrm{Ra})$. The equations involved in this study are [24]:

$$
\begin{aligned}
& \overline{K_{t}}=1+n\left(\frac{R_{a}}{\bar{\rho}}\right)\left(\frac{R_{y}}{R_{z}}\right) \\
& \overline{K_{f}}=1+q\left(\overline{K_{t}}-1\right) \\
& q=\frac{1}{\left(1+\frac{\gamma}{\bar{\rho}}\right)}
\end{aligned}
$$

where $n$ is a constant that relates the load type applied to the material. According to Neuber rule, $n=1$ to shear loads, and $n=2$ to tensile loads. Ra, Ry and Rz 
is the average roughness, peak-to-valley height and 10point roughness, respectively. The parameter $\rho$ corresponds to the effective radius profile valley. $\overline{K_{f}}$ and $q$ correspond to effective fatigue stress concentration factor and notch sensitivity, respectively. Finally, $\gamma$ is a constant related to the material and to the tensile strength limit [24]. In this work, the values of $n$ and $\gamma$ are equal to 2 and 0087 , respectively.

Table 1 shows the roughness parameters calculated for Ti6Al4V alloy at the untreated, PIII - 390 and PIII - 800 conditions.

Table 1. Main surface roughness parameters estimated for untreated, PIII-390 and PIII-800 treated conditions.

\begin{tabular}{|c|c|c|c|c|}
\hline Sample & $\mathbf{R a}(\boldsymbol{\mu m})$ & $\mathbf{R z}(\boldsymbol{\mu m})$ & $\mathbf{R y}(\boldsymbol{\mu m})$ & $\boldsymbol{\rho}(\boldsymbol{\mu m})$ \\
\hline Ti6Al4V & $1.5 \pm 0.2$ & $10.4 \pm 2.2$ & $12.6 \pm 3.4$ & $25.8 \pm 8.9$ \\
\hline $3 \mathrm{IP}-390$ & $1.5 \pm 0.0$ & $11.1 \pm 1.9$ & $14.9 \pm 7.1$ & $19.8 \pm 1.7$ \\
\hline $3 \mathrm{IP}-800$ & $1.4 \pm 0.3$ & $8.9 \pm 2.5$ & $10.2 \pm 3.7$ & $18.0 \pm 2.3$ \\
\hline
\end{tabular}

Table 2 presents the notch sensitivity parameters based on the mathematical model of Arola and Ramulu and Neuber rule [24].

Table 2. Notch sensitivity parameters.

\begin{tabular}{|c|c|c|c|}
\hline Sample & $\overline{\boldsymbol{K}_{\boldsymbol{t}}}$ & $\boldsymbol{Q}$ & $\overline{\boldsymbol{K}_{\boldsymbol{f}}}$ \\
\hline Ti6A14V & 1.14 & 0.23 & 1.03 \\
\hline $3 \mathrm{IP}-390$ & 1.20 & 0.19 & 1.04 \\
\hline $3 \mathrm{IP}-800$ & 1.17 & 0.17 & 1.03 \\
\hline
\end{tabular}

Figures 7 shows the relationship between notch sensitivity $q$ and average roughness Ra.

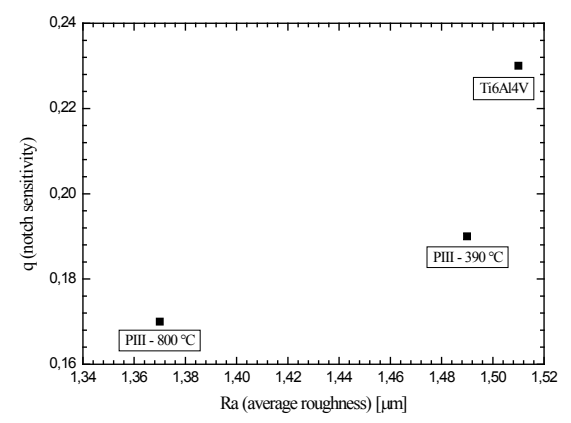

Fig. 7. Notch sensitivity analysis: $q$ vs Ra.
Figure 8 shows the relationship between the stress concentration factors, $\overline{K_{t}}$ and $\overline{K_{f}}$, and average roughness $\mathrm{Ra}$.

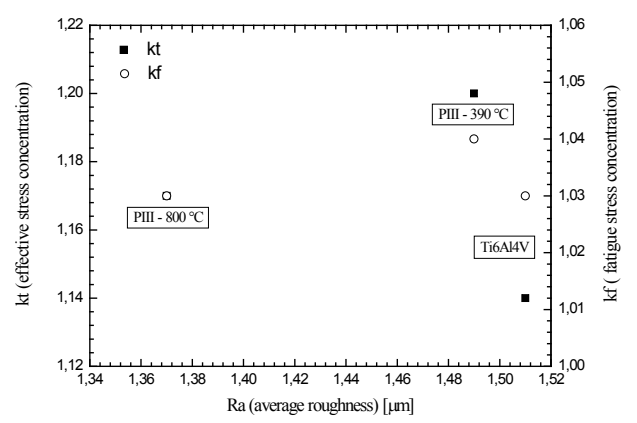

Fig. 8. Notch sensitivity analysis: $\overline{k_{t}}$ vs Ra and $\overline{k_{f}}$ vs Ra .

Tables 1 and 2 analysis together with Figures 7 and 8 show that the roughness increase raises the notch sensitivity. This is an usual observation, since the surface roughness acts as a defect, increasing the stress concentration at the surface and accelerating the crack nucleation process. About the stress concentration factors, it was observed that the highest values of $\overline{K_{t}}$ and $\overline{K_{f}}$ are related with the PIII -390 condition.

Correlating the fatigue results with the notch sensitivity analyzes and with the fracture mechanisms, they can be explained as follows:

- the first point to be raise is, for this set of studied samples, Ra does not influence the fatigue behavior of Ti6Al4V alloy in all the experimental conditions. If the average roughness contributes to the increase of stress concentrators points, accelerating the crack nucleation, it should be observed in terms of fatigue strength, an increase in fatigue life with the PIII treatments following the scheme: $\mathrm{N}_{\text {Ti6Al4V }}<\mathrm{N}_{\text {PIII - 390 }}<\mathrm{N}_{\text {PIII - 800; }}$;

- in the PIII - 390 condition, the parameter that controls the fatigue fracture mechanisms is the strain generated in the titanium crystalline lattice by solid solution. This strain has reached a limit, due to the high frequency adopted, $f=1.5 \mathrm{kHz}$, resulting in microdeformations and microcracks to relieve strain in the crystal lattice [25]. Interestingly, the parameter $\overline{K_{f}}$, that is related to a stress concentration factor is the highest for this condition. Mathematically corroborate the hypothesis that the titanium crystalline lattice strained in such a level that, to relieve, generated on the sample surface pre-microcrack. If the fatigue failure mechanism is the nucleation and growth of a crack, the surface treatment carried out in this condition eliminated the nucleation process. These microcracks generated in the order of a few interplanar distances, when subjected to cyclic loading and combined with the favorable crystallographic orientations of dislocations slipping, coalesce and contribute to crack propagation [26, 27], reducing the fatigue life;

- in the PIII - 800 condition, the morphology transformation from annealed microstructure to Widmanstätten was responsible for the decrease in the 
Ti6A14V alloy mechanical strength. This microstructure did not offer resistance to crack propagation. Ra and $\overline{K_{f}}$ values show that the surface parameters are suitable for fatigue application. The microstructure presented here is coarse grained, $350 \mu \mathrm{m}, 90$ times larger than the size of the grains in the annealed condition. The coarse-grained microstructure contributes to a decreased in fatigue toughness, favoring crack propagation and reducing the component lifetime. Moreover, the $\alpha+\beta$ colonies present on Ti6A14V alloy with lamellar morphology do not offer barrier to the growth of the crack since the effective slip distance is not between lamellae and colonies but between the coarse grains of prior $\beta$ phase. Regarding to nitrogen surface implantation, the nitride layer composed of nitrides $+\alpha$ case further contributes to embrittlement of the Ti6Al4V alloy. The nitrogen diffusion region, known as $\alpha$ case is characterized by a surface layer composed only of $\alpha$ phase, hexagonal crystal structure known to have only 5 slip systems. The thin nitride layer, $1.4 \mu \mathrm{m}$, could act as a hard compound capable of slowing the crack nucleation process $[21,26$, 27]. Its effect, however, can be considered negligible due to the contributions of the coarse grained and $\alpha$ case that embrittled the Ti6Al4V alloy and dropped the fatigue life of Ti6Al4V alloy.

Recent papers showed that PIII treatment increases the fatigue life of steels and aluminum alloys, both applied as landing gear components [28, 29]. And when this treatment had a deleterious effect on the fatigue behavior compared to the base material, this drop in performance was lower than that caused by other more conventional surface treatments $[25,29,30,31]$.

\section{Conclusions}

This study reported the results involving untreated and PIII treated Ti-6AL-4V alloy, at different work temperatures, and submitted to axial fatigue loading.

Resistance to fatigue decreased with PIII treatments in both temperatures. The fatigue resistance decreasing was of 50 times for PIII - 390 condition and 346 times for PIII -800 condition. At $390{ }^{\circ} \mathrm{C}$, the treatment created deformation regions and microcracks on surface due to nitrogen implantation that formed solid solution with titanium and imposed lattice strains on the crystal lattice. At $800{ }^{\circ} \mathrm{C}$, bulk ductility decrease, increasing of $\alpha \mathrm{Ti}$ proportion in microstructure due to $\alpha$ case formation and the presence of a ceramic layer dropped fatigue resistance of Ti-6A-4V alloy.

More studies should be done about PIII and fatigue behavior, varying temperature and frequency, in order to improve the fatigue life of metallic alloys applied in structural components. It is also worth considering a route of heat treatment to provide the best combination of grain size and fracture toughness in a Widmanstätten type morphology. Finally, the effect of the treatment temperature can only be evaluated in a situation in which the bulk microstructure is maintained during the treatment.

\section{Acknowledgments}

The authors would like to acknowledge FAPESP (Fundação de Amparo à Pesquisa do Estado de São Paulo) and $\mathrm{CNPq}$ (Conselho Nacional de Desenvolvimento Científico e Tecnológico) for their continued financial support (Process FAPESP 2015/00331-2, CNPQ 303832/2014-2).

\section{References}

1. R.R. Boyer, Adv. Perform. Mater., 2 (1995).

2. C. Cui, B. Hu, L. Zhao, S. Liu, Mater. Des., 32 (2011).

3. V.M.C.A. Oliveira, C. Aguiar, A.M. Vazquez, A. Robin, M.J.R. Barboza, Corros. Sci., 88 (2014).

4. O. Schauerte, Adv. Eng. Mater., 5 (2003).

5. R.G. Bonora, H.J.C. Voorwald, M.O.H. Cioffi, G.S. Junior, L.F. V Santos, Procedia Eng. 2 (2010).

6. W.J. Evans, 243 (1998).

7. J.C. Williams, E.A. Starke, Acta Mater. 51 (2003).

8. L. Chen, Y. Du, X. Xiong, K.K. Chang, M.J. Wu, Int. J. Refract. Met. Hard Mater. 29 (2011).

9. M.Y.P. Costa, M.O.H. Cioffi, M.L.R. Venditti, H.J.C. Voorwald, Procedia Eng. 2 (2010).

10. C. Fei, Z. Hai, C. Chen, X. Yangjian, Prog. Org. Coatings. 64 (2009).

11. A. Höling, L. Hultman, M. Odén, J. Sjölén, L. Karlsson, Surf. Coatings Technol. 191 (2005).

12. P. Pérez, Surf. Coatings Technol. 191 (2005).

13. H.J.C. Voorwald, L.F.S. Vieira, M.O.H. Cioffi, Procedia Eng. 2 (2010).

14. G.F. Gomes, M. Ueda, H. Reuther, E. Richter, A.F. Beloto, Surf. Coatings Technol. 196 (2005).

15. K. Kostov, M. Ueda, M. Lepiensky, P. Soares, G. Gomes, M. Silva, H. Reuther, Surf. Coatings Technol. 186 (2004).

16. C.B. Mello, M. Ueda, M.M. Silva, H. Reuther, L. Pichon, C.M. Lepienski, Wear. 267 (2009).

17. G. Silva, M. Ueda, C. Otani, C.B. Mello, C.M. Lepienski, Surf. Coatings Technol. 204 (2010).

18. L. Kuncická, R. Kocich, T.C. Lowe, P. Mater Sci. 88 (2017).

19. X. Tian, P.K. Chu, Phys. Letter. 277 (2000).

20. A.V. Byeli, S.K. Shikh, V.V. Khatko, Wear 159 (1992).

21. L. Wanying, L. Yuanhua, C. Yuhai, S. Taihe, A. Singh, Rare Metal Mater Eng. 46 (2017).

22. L. Jianhui, Z. Ruilong, W. Yaobing, L. Shanshan, Theor. App. Fract. Mech. 93 (2018) 
23. D. Arola, M. Ramulu, J. Compos. Mater. 33, 02 (1999)

24. D. Arola, C.L. Williams, Inter. J. Fatigue 24 (2002).

25. V.M.C.A. Oliveira, M.O.H. Cioffi, M.J.R. Barboza, R. Landers, B. Schmitt, D.C.A.R. Tapia, H.J.C. Voorwald, Inter. J. Fatigue 109 (2018)

26. K.L. Biavant, S. Pommier, C. Prioul, Fatigue Fract. Eng. Mater. Struct. 25 (2002).

27. K.S. Chan, Inter. J. Fatigue, 32 (2010).

28. R. Bonora, M.O.H. Cioffi, H.J.C. Voorwald, J. Physic.: Conf. Series 843 (2017).

29. T. A. Minto, V.M.C.A. Oliveira, H.J.C. Voorwald, Inter. J. Fatigue 103 (2017).

30. H.J.C. Voorwald, M.P. Silva, M.Y.P. Costa, M.O.H. Cioffi, Fatigue Fract Eng Mater Struct 32 (2009).

31. R.C. Souza, H.J.C. Voorwald, M.O.H. Cioffi, Surf Coat Technol 203 (2008). 